\title{
Changes in erythrocyte membrane permeability induced by verapamil, chlorpromazine, and their combinations with amphotericin B
}

\author{
AGNIESZKA KNOPIK-SKROCKA, JÓZEF BIELAWSKI, SZYMON CHOWAŃSKI \\ and PAULINA WALKOWIAK
}

\begin{abstract}
Department of Cell Biology, Adam Mickiewicz University, Umultowska 89, 61-614 Poznań, Poland
\end{abstract} Corresponding author: Agnieszka Knopik-Skrocka, askro@amu.edu.pl

(Received on 11 May 2010; Accepted on 25 November 2011)

\begin{abstract}
Hemolysis induced by 2 amphipathic agents, verapamil and chlorpromazine, was investigated in various incubation conditions. Changes in absorbance of erythrocyte suspension were monitored by absorption spectrophotometry at a wavelength of $590 \mathrm{~nm}$. The hemolysis induced by verapamil or chlorpromazine is of the permeability type. The resistance of erythrocytes to verapamil is much higher than their resistance to chlorpromazine. No evident difference is found between human and pig erythrocytes in their resistance to verapamil. Only a small decrease in the rate of hemolysis induced by verapamil is observed in isotonic $\mathrm{CaCl}_{2}, \mathrm{MgCl}_{2}$ or $\mathrm{K}_{2} \mathrm{SO}_{4}$ solutions, compared to $160 \mathrm{mM} \mathrm{KCl}$ (the standard incubation medium). The changes in hemolytic activity of chlorpromazine in the presence of the divalent cations and anions are less evident. No decrease in hemolytic activity of chlorpromazine and verapamil is observed in the sucrose medium. The hemolytic activity of both the agents increases when they act in combination with polyene antibiotic amphotericin B. The results indicate a strong synergy between amphotericin B and verapamil or chlorpromazine. By contrast, a combined effect of verapamil and chlorpromazine on erythrocytes leads to a decrease in their hemolytic activity. This indicates antagonism between verapamil and chlorpromazine.
\end{abstract}

Keywords: verapamil, chlorpromazine, amphotericin B, synergy, erythrocyte membrane hemolysis

\section{INTRODUCTION}

Verapamil is a calcium channel blocker, commonly used in cardiovascular diseases (McTAVISH \& Sorkin 1989). It may act as a chemosensitizer of p-glycoprotein or multidrug resistance protein 1 - MRP1 (SPEELMANS et al. 1995; SALERNo et al. 2004, Meier et al. 2006; PerRotTon et al. 2007), which are membrane proteins responsible for multidrug resistance (MDR). Verapamil may lead to the reversal of MDR by direct binding to p-glycoprotein (MeIER et al. 2006) or by changing the membrane fluidity and permeability (DroRI et al. 1995; PAJEVA et al. 1996).

Chlorpromazine is a tricyclic phenothiazine derivative, widely used in the treatment of neurological disorders like schizophrenia (LiEBERMAN et al. 2003). It may act 
as a chemosensitizer of p-glycoprotein (AAnismaA \& Seelig 2007) and it enhances the cytotoxic effect of some anticancer drugs (Wadkins \& Houghton 1993; BeBAwY et al. 2001).

Both the amphipathic agents, verapamil and chlorpromazine, show a high affinity to membrane anionic phospholipids located within the inner layer of the cell membrane (Anteneodo et al. 1995; SpeElmans et al. 1995; Chen et al. 2003; WiśniewsKa \& WolnickA-Glubisz 2004; PickHolz et al. 2007). Studies on human erythrocytes have shown that both the agents induce the formation of stomatocytes, i. e. invaginated erythrocytes (Deuticke 1968; Schreier et al. 1992; Chen et al. 1997; Suwalsky et al. 2008, 2010). According to the bilayer couple hypothesis (SHEETz \& Singer 1974), stomatocytosis can be explained by favorable interaction of both the agents with the inner layer of the erythrocyte membrane.

The interaction of verapamil and chlorpromazine with membranes is modified by changes in phospholipid distribution or cholesterol content (MASON et al. 1992; CASTAING et al. 2003a; WiśnIEWSKA \&WolniCKA-Glubisz 2004; WolniCKA-Glubisz et al. 2009). Membrane potential profile (PoHL et al. 1998) and ionic strength (CASTAING et al. 2003b) strongly influence the membrane activity of verapamil. Differences in membrane activity of chlorpromazine have been found for its neutral and protonated state (Wajnberg et al. 1988; Bennouna et al. 1997; Ahyayauch et al. 2003; WIŚNIEWSKA \& WolNiCKA-GLUBISZ 2004).

The effect of verapamil and chlorpromazine on the membrane strongly depends on their concentrations (ZaChOWSKI \& DuRAND 1988; Hagerstrand et al. 2006; Michalak et al. 2007; Watts \& Handy 2007; Suwalsky et al. 2008). At high concentrations, verapamil and chlorpromazine induce hemolysis (LIEBER et al. 1984; MoRimoto et al. 1995; WATts \& HANDy 2007; SuwAlsky et al. 2008). There are some studies on the influence of physicochemical conditions of incubation medium on the hemolytic activity of verapamil and chlorpromazine (LIEBER et al. 1984; MoRIMOTO et al. 1995; Ahyayauch et al. 2003; WatTs \& Handy 2007). However, the mechanism of the increase in membrane permeability induced by the amphipaths is still not clear.

The results of our previous studies on mammalian erythrocytes treated with amphipathic polyene antibiotic amphotericin B have revealed a high dependence of the polyene hemolytic activity on the species and specimen features of the erythrocyte membrane (KNOPIK-SKRocka \& BielawsKi 2002, 2005; KNOPIK-SKrockA et al. 2003, 2006; KNOPIK-SKROCKA \& BuLDAŃCZYK 2004). The rate of hemolysis induced by amphotericin B is highly decreased in media with different-sized markers (KNOPIKSkrocka \& Bielawski 2002; KnOPIK-SKrocka et al. 2003, 2007; KNOPIK-SKrocka \& BuLDAŃCZYK 2004). The hemolytic activity of amphotericin B is an effect of formation of antibiotic-sterol channels (BRAJTBURG et al. 1980; CyBulska et al. 1995). Our earlier results suggested that these channels differ in diameter and selectivity.

In the present paper, the hemolytic activity of verapamil and chlorpromazine was investigated in incubation media with various ions or sucrose and the results are compared with those obtained for amphotericin B. With regard to a high affinity of amphotericin B to membrane cholesterol (CHARBONNEAU et al. 2001) and its competition for membrane target with other polyene antibiotics (BRAJTBURG et al. 1980), changes in the hemolytic activity of verapamil and chlorpromazine as a result of their 
combined action with amphotericin B have been investigated. The hemolytic effect of combined action of verapamil with chlorpromazine has been also examined.

\section{MATERIALS AND METHODS}

\section{Preparation of erythrocyte suspension}

The 1-day concentrate of human erythrocytes in a polyvinyl bag, with reduced plasma content, was obtained from a blood bank. The erythrocyte concentrate was stored at $4^{\circ} \mathrm{C}$ with the addition of CPD (citric acid monohydrate $206 \mathrm{mg}$, sodium citrate dihydrate $1.66 \mathrm{~g}$, sodium dihydrogenophosphate monohydrate $140 \mathrm{mg}$, glucose monohydrate $1.61 \mathrm{~g}$, water $63 \mathrm{~mL}$ ) and ADSOL formula (sodium chlorate 900 $\mathrm{mg}$, glucose monohydrate $2.2 \mathrm{~g}$, adenine $2.7 \mathrm{mg}$, mannitol $750 \mathrm{mg}$, water $100 \mathrm{~mL}$ ). After $24 \mathrm{~h}$, the concentrate was used to prepare the erythrocyte suspension. Pig blood was obtained from a slaughterhouse freshly after venipuncture. As described earlier (KNOPIK-SKRocka et al. 2003), pig blood was stored for up to $24 \mathrm{~h}$ at $4{ }^{\circ} \mathrm{C}$ in the presence of citrate and glucose. The procedure of erythrocyte suspension preparation was the same as described earlier (KNOPIK-SKRockA \& BIELAwsKi 2005; KNOPIK-SKRocKA et al. 2007). The final concentration of erythrocytes suspended in the incubation medium was $0.25 \mu$ l of total erythrocyte volume $/ \mathrm{mL}\left(2.8 \times 10^{6}\right.$ erythrocytes $\left./ \mathrm{mL}\right)$.

\section{Preparation of stock solutions}

Verapamil hydrochloride and chlorpromazine hydrochloride were obtained from Sigma-Aldrich. The stock solution of verapamil in distilled water was $20 \mathrm{mM}$ and that of chlorpromazine was $7.5 \mathrm{mM}$. Amphotericin B was from Fluka, and its 0.54 $\mathrm{mM}$ stock solution was prepared in dimethylformamide (Fluka). The dimethylformamide in the incubation medium had no effect on the erythrocytes. All the stock solutions were prepared freshly before experiments.

\section{Incubation conditions}

The standard incubation medium of erythrocytes was $160 \mathrm{mM} \mathrm{KCl}$. This solution, as well as the other media tested $\left(107 \mathrm{mM} \mathrm{CaCl}_{2}, \mathrm{MgCl}_{2}, \mathrm{~K}_{2} \mathrm{SO}_{4}\right.$, and $300 \mathrm{mM}$ sucrose), were taken as isoosmotic to the cell interior. The concentration of the stock solution of the salts or sucrose was twice that of isotonicity. The final concentration was obtained by mixing an appropriate volume of the stock solution of the salt, the hemolytic agent and distilled water.

The experiments were performed at $37^{\circ} \mathrm{C}$. As described earlier (KNOPIK-SKROCKA \& BielawsKi 2005; KNOPIK-SKROCKA et al. 2007), erythrocytes were incubated without any buffer added. The $\mathrm{pH}$ of the incubation medium was 6.8. This value was obtained by addition of $160 \mathrm{mM} \mathrm{KOH}$ or $\mathrm{HCl}$.

\section{Measurements of hemolysis}

In standard experiments, the required amounts of verapamil or chlorpromazine stock solutions were preincubated in isoosmotic $\mathrm{KCl}$ for $10 \mathrm{~min}$ at $37^{\circ} \mathrm{C}$ in test tubes (inner diameter of $14 \mathrm{~mm}$ ). Total volume of the medium in the tubes was $10 \mathrm{~mL}$. Next, the erythrocyte suspension was added and mixed with the incubation medium. 
The absorbance was measured at selected time intervals. The suspension was mixed frequently to avoid erythrocyte sedimentation. In all the experiments, the erythrocyte suspension absorbance was measured in the control tube, without the hemolytic agent added.

The absorbance of the erythrocyte suspension was measured as described previously (KNOPIK-SKROCKA \& BIELAWSKI 2005) with the use of spectrophotometer Epoll 2000 Eco (EMCO, Warsaw) at $\lambda=590 \mathrm{~nm}$. At this wavelength, the absorbance of lysed erythrocytes is very low and independent of $\mathrm{pH}$. Most of the absorbance is due to light scattering, which decreases with increasing in volume and lysis of erythrocytes. Participation of light absorption in the absorbance is low.

\section{Estimation of erythrocyte resistance to verapamil and chlorpromazine}

The resistance of erythrocytes to verapamil or chlorpromazine was evaluated as the agent concentration that induces $50 \%$ erythrocyte hemolysis during $30 \mathrm{~min}$ of incubation $\left(\mathrm{C}_{50}\right)$. The $\mathrm{C}_{50}$ value was interpolated from the agent concentration-hemolysis rate curve (KNOPIK-SKROCKA \& BIELAWSKI 2005).

Statistical significance between the groups of results compared was determined using Student's $t$ test. $P<0.05$ was taken as the threshold of significance.

\section{RESULTS}

The effect of verapamil on the absorbance of the human erythrocyte suspension in standard incubation conditions is presented in Fig. 1. After addition of erythrocytes at zero time of incubation, there is a slow drop in absorbance. It is followed by a faster drop in absorbance, reaching finally the lowest value (minimal absorbance). During the initial slower drop, swelling of erythrocytes occurs. When the critical volume of the cells is exceeded, hemolysis occurs, monitored as the second, faster drop in absorbance. At $4 \mathrm{mM}$ verapamil, the rate of absorbance drop is rather low (Fig. 1). The first phase, corresponding to erythrocyte swelling, lasts $60 \mathrm{~min}$ and the absorbance value decreases from about 0.570 to 0.420 . Next, the rate of absorbance drop increases due to cell lysis, leading to complete hemolysis at the absorbance of 0.030 . Complete hemolysis takes place at about $100 \mathrm{~min}$.

The increase in verapamil concentration is associated with an increase in the rate of human erythrocyte swelling and lysis (Fig. 1). All the cells are lysed at both high and low verapamil concentrations. Similar results were obtained for pig erythrocytes treated with verapamil (curves not shown).

The kinetics of hemolysis induced by chlorpromazine (Fig. 2) does not differ from the kinetics of hemolysis caused by verapamil. The process expressed by this type of time-absorbance curves (Figs. 1-2) can be classified as the permeability type of hemolysis (BIELAWSKI 1990). This type of hemolysis allows the calculation of the rate of hemolysis as the reciprocal of the time $\left(\mathrm{min}^{-1}\right)$ at which $50 \%$ of erythrocytes are lysed. If correction is made for swelling, it corresponds to the absorbance decrease equal to $55 \%$ of the maximal absorbance decrease. The dependence of the rate of human erythrocyte hemolysis on verapamil concentration in standard incubation conditions is presented in Fig. 3. The slope of the curve increases to a concentration 


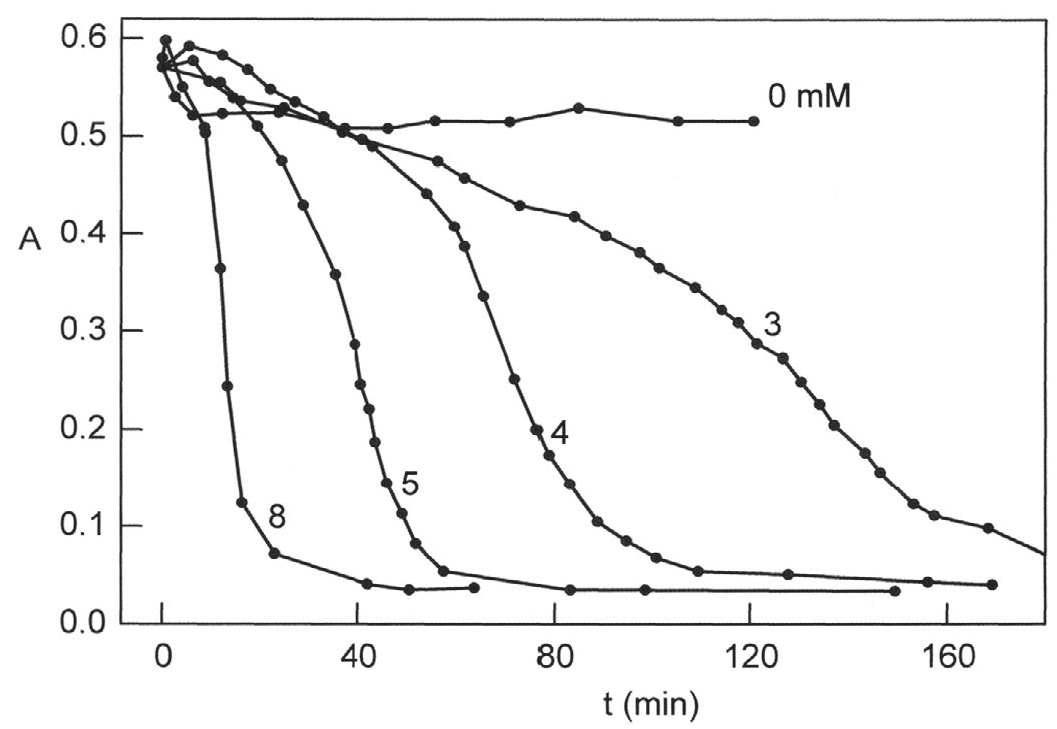

Fig. 1. Influence of verapamil concentration on the dependence of human erythrocyte suspension absorbance (A) on incubation time (t). Incubation medium: $160 \mathrm{mM} \mathrm{KCl}, 37^{\circ} \mathrm{C}$. Verapamil concentrations are given in $\mathrm{mM}$ in the figure

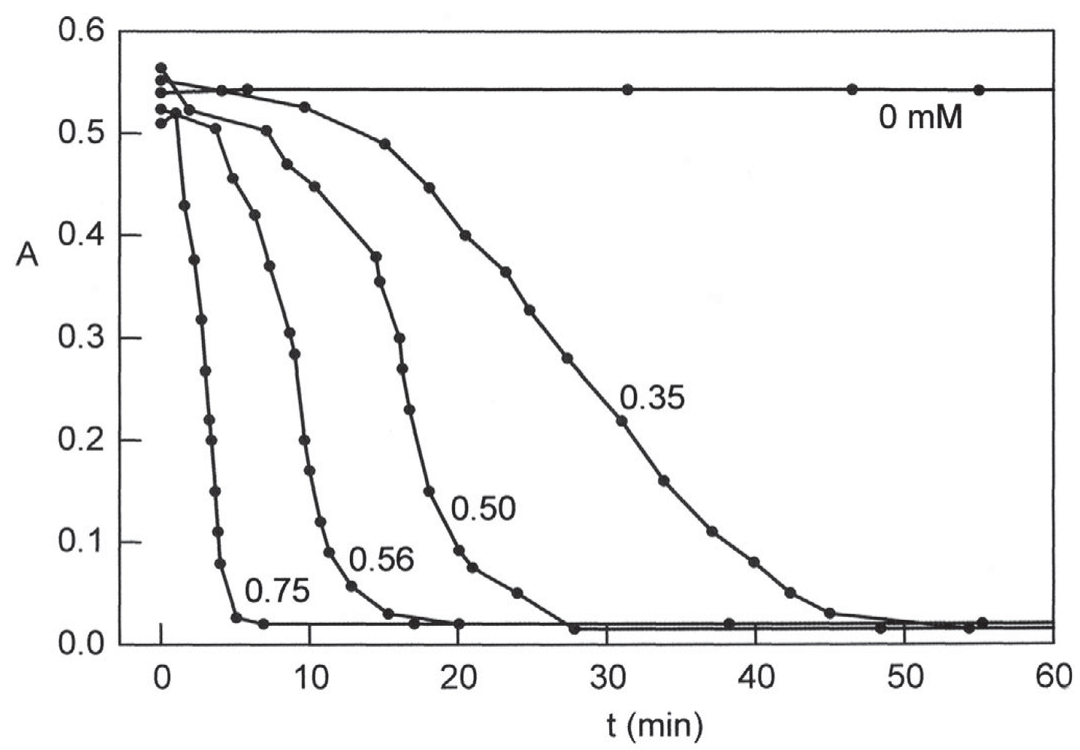

Fig. 2. Influence of chlorpromazine concentration on the dependence of human erythrocyte suspension absorbance $(\mathrm{A})$ on incubation time $(\mathrm{t})$. Incubation medium: $160 \mathrm{mM} \mathrm{KCl}, 37^{\circ} \mathrm{C}$. Chlorpromazine concentrations are given in $\mathrm{mM}$ in the figure 


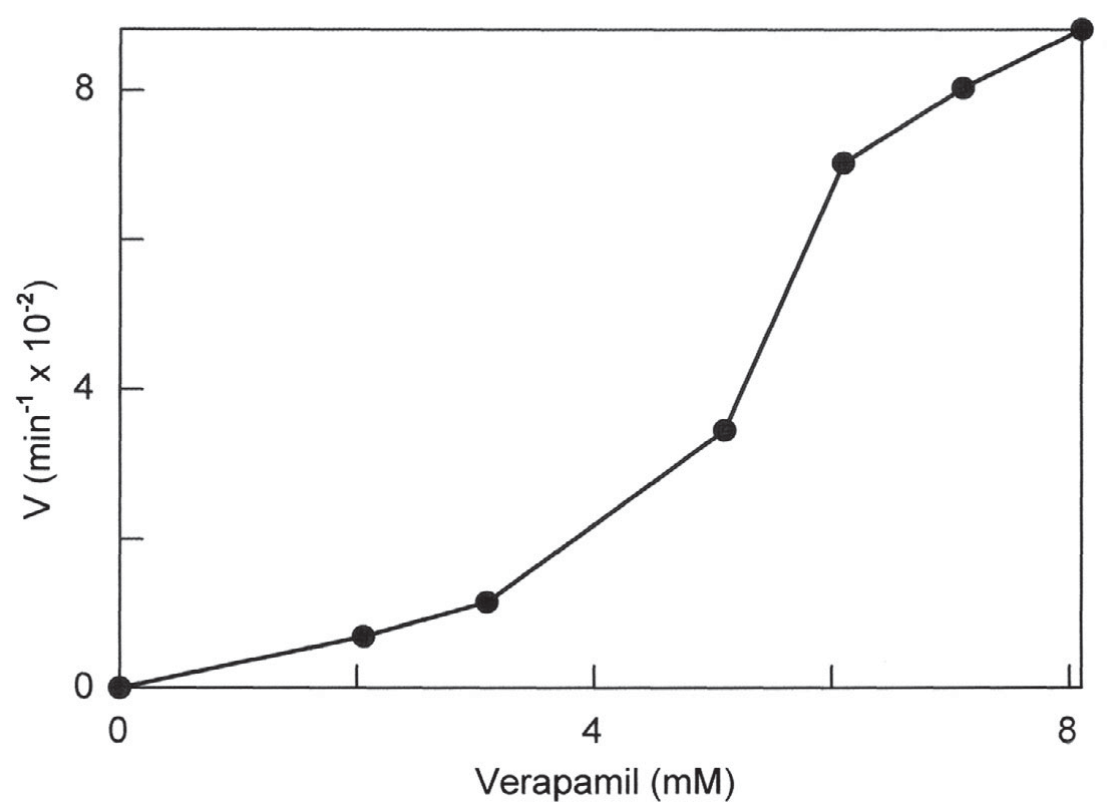

Fig. 3. Influence of verapamil concentration on the rate of human erythrocyte hemolysis (V). Incubation medium: $160 \mathrm{mM} \mathrm{KCl}, 37^{\circ} \mathrm{C}$

of about $6 \mathrm{mM}$ verapamil. At higher concentrations, the slope of the curve gradually decreases. This decrease may be an indication of saturation of the membranes with verapamil. Interpolation of the concentration-rate curves, such as the one in Fig. 3, enables evaluation of the resistance of the erythrocytes to verapamil and chlorpromazine $\left(\mathrm{C}_{50}\right)$. The resistance was calculated as the concentration that induces lysis of $50 \%$ erythrocytes during $30 \mathrm{~min}$ (Table 1). The hemolytic activity of verapamil to human and pig erythrocytes does not differ significantly. It is much lower than the hemolytic activity of chlorpromazine.

There are relatively small differences in the hemolytic activity of verapamil in the media of various chemical compositions. With regard to high erythrocyte resistance to verapamil, we estimate the influence of the medium chemical composition on verapamil hemolytic activity in the experiments with constant verapamil concentration and various concentrations of the solutions tested. The isotonicity of the media was kept constant by mixing appropriate volumes of their isoosmotic solutions with $160 \mathrm{mM} \mathrm{KCl}$. The constant $5 \mathrm{mM}$ verapamil was chosen as close to the $\mathrm{C}_{50}$ value. The kinetics of hemolysis induced by this concentration of verapamil in increasing concentrations of $\mathrm{CaCl}_{2}$ in the incubation medium is presented in Fig. 4. An increase in the time of hemolysis is observed when $\mathrm{Ca}^{2+}$, concentration is increased. At $0 \mathrm{mM}$ $\mathrm{Ca}^{2+}$ the complete hemolysis is finished after about $50 \mathrm{~min}$. When the concentration of $\mathrm{Ca}^{2+}$ equals to $11 \mathrm{mM}$, the time of hemolysis increases to about $100 \mathrm{~min}$. At higher 
Table 1. Resistance $\left(\mathrm{C}_{50}\right)$ of human and pig erythrocytes to verapamil, chlorpromazine and amphotericin $\mathrm{B}$ in $160 \mathrm{mM} \mathrm{KCl}$

\begin{tabular}{cccc}
\hline Erythrocytes & $\begin{array}{c}\text { Verapamil } \\
\mathrm{C}_{50}(\mathrm{mM})\end{array}$ & $\begin{array}{c}\text { Chlorpromazine } \\
\mathrm{C}_{50}(\mathrm{mM})\end{array}$ & $\begin{array}{c}\text { Amphotericin B } \\
\mathrm{C}_{50}(\mathrm{mM})\end{array}$ \\
\hline Human & $4.785 \pm 0.664(10)$ & $0.277 \pm 0.062(8)$ & $0.00198 \pm 0.000318(10)^{\mathrm{a}}$ \\
Pig & $4.417 \pm 0.461(7)$ & - & $0.00090 \pm 0.0010(11)^{\mathrm{b}}$ \\
\hline
\end{tabular}

$\mathrm{C}_{50}$ values are means $\pm \mathrm{SD}$ calculated from $(N)$ measurements.

${ }^{\text {a}}$ Results from Knopik-Skrocka \& Bielawski (2005).

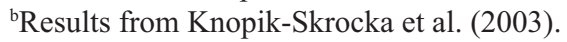

For human erythrocytes, pair-wise differences between the 3 agents are significant at $P<0.001$. Differences between human and pig erythrocytes are not significant for verapamil but significant at $P<0.01$ for amphotericin B.

concentrations of $\mathrm{Ca}^{2+}$, there is a slower drop in absorbance, and the hemolysis is incomplete in $200 \mathrm{~min}$.

No evident increase in absorbance of the erythrocyte suspension is observed before the hemolysis induced by verapamil. Similar results to those in $\mathrm{CaCl}_{2}$ were obtained in the other media tested. Fig. 5 presents the dependence of the rate of hemolysis induced by $5 \mathrm{mM}$ verapamil on $\mathrm{CaCl}_{2}, \mathrm{MgCl}_{2}$ and $\mathrm{K}_{2} \mathrm{SO}_{4}$ concentration in the incubation medium. The decrease in the rate of hemolysis is beginning with the low concentrations of $\mathrm{Ca}^{2+}, \mathrm{Mg}^{2+}$ and $\mathrm{SO}_{4}{ }^{2-}$. The main difference between the action of these ions consists in the final decrease in the rate of hemolysis. The ratios of the rate of hemolysis induced by verapamil in the solutions tested to that in $\mathrm{KCl}$ are presented in Table 2. Divalent cations are slightly more effective than $\mathrm{SO}_{4}{ }^{2-}$ in decreasing of verapamil activity.

Table 2. Effect of replacing $\mathrm{KCl}$ in the incubation medium with isoosmotic solutions of several salts and sucrose on the rate of human erythrocyte hemolysis induced by $5.0 \mathrm{mM}$ verapamil

\begin{tabular}{ll}
\hline Incubation medium & $\mathrm{V} / \mathrm{V}_{\mathrm{KCl}}{ }^{*}$ \\
\hline $107 \mathrm{mM} \mathrm{CaCl}_{2}$ & 0.27 \\
$107 \mathrm{mM} \mathrm{MgCl}_{2}$ & 0.23 \\
$107 \mathrm{mM} \mathrm{K}_{2} \mathrm{SO}_{4}$ & 0.65 \\
$300 \mathrm{mM}$ sucrose & 1.32 \\
\hline
\end{tabular}

* Ratio of the rate of hemolysis induced by verapamil in the given medium to that in $\mathrm{KCl}$. The values are means of 2 measurements 


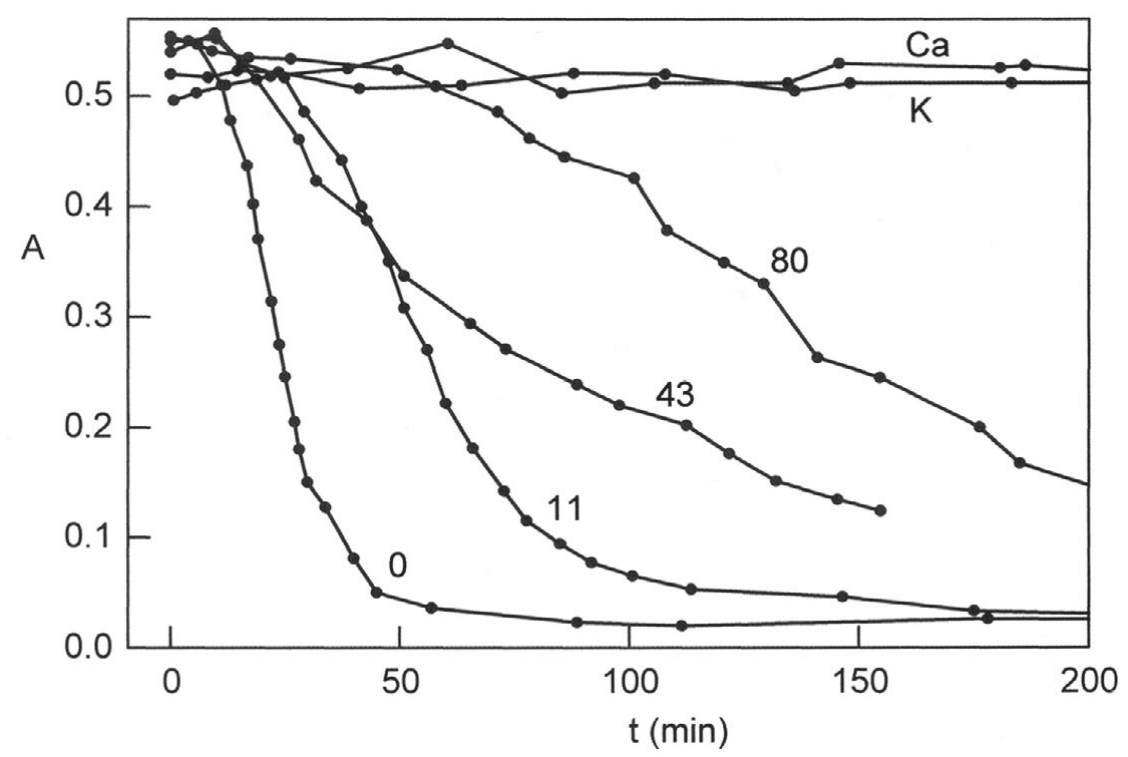

Fig. 4. Effect of $\mathrm{CaCl}_{2}$ concentration in the incubation medium on the dependence of human erythrocyte suspension absorbance $(A)$ on incubation time $(t)$. Verapamil concentration $5 \mathrm{mM}, 37^{\circ} \mathrm{C}$. Concentrations of $\mathrm{CaCl}_{2}$ are given in $\mathrm{mM}$ in the figure. $\mathrm{K}=160 \mathrm{mM} \mathrm{KCl}$ without verapamil. $\mathrm{Ca}=107$ $\mathrm{mM} \mathrm{CaCl}{ }_{2}$ without verapamil

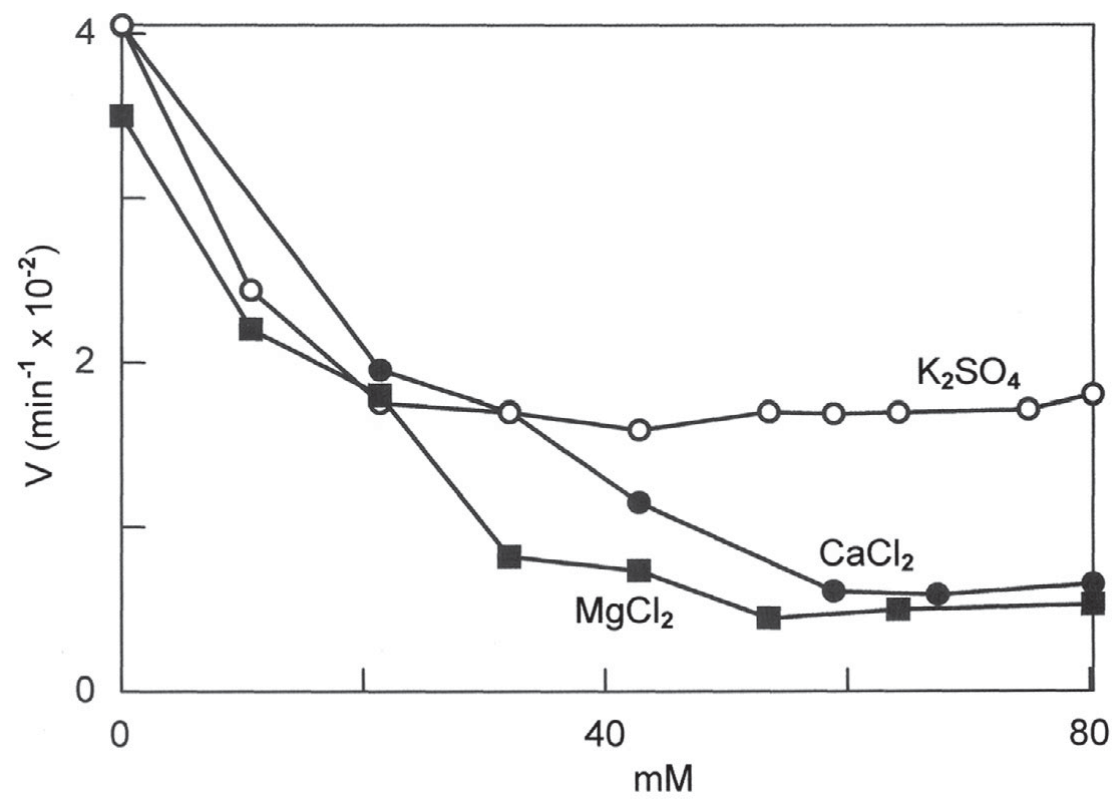

Fig. 5. Effect of $\mathrm{CaCl}_{2}, \mathrm{MgCl}_{2}$ and $\mathrm{K}_{2} \mathrm{SO}_{4}$ concentration in the incubation medium on the rate of hemolysis $(V)$ induced by $5 \mathrm{mM}$ verapamil, $37^{\circ} \mathrm{C}$ 
The changes in hemolytic activity of chlorpromazine caused by modifications of the chemical composition of the incubation medium are even less evident than those obtained for verapamil. Like in the standard incubation medium, the $\mathrm{C}_{50}$ was calculated in all other media tested from interpolation of concentration-rate curves. The final results are presented as the ratios of $\mathrm{C}_{50}$ in $107 \mathrm{mM} \mathrm{CaCl}, \mathrm{MgCl}_{2}, \mathrm{~K}_{2} \mathrm{SO}_{4}$ and in $300 \mathrm{mM}$ sucrose to the $\mathrm{C}_{50}$ in $\mathrm{KCl}$ (Table 3). Only a very small increase in the resistance of the erythrocytes to chlorpromazine is observed in the presence of 107 $\mathrm{mM} \mathrm{CaCl}, \mathrm{MgCl}_{2}$ and $\mathrm{K}_{2} \mathrm{SO}_{4}$. In $300 \mathrm{mM}$ sucrose, the resistance of erythrocytes is lower than in the standard medium.

Table 3. Effect of replacing $\mathrm{KCl}$ in the incubation medium with isoosmotic solutions of several salts and sucrose on the resistance of human erythrocytes to chlorpromazine

\begin{tabular}{|c|c|}
\hline Incubation medium & $\mathrm{C}_{50} / \mathrm{C}_{50 \mathrm{KCl}}{ }^{*}$ \\
\hline $107 \mathrm{mM} \mathrm{CaCl}_{2}$ & 1.28 \\
\hline $107 \mathrm{mM} \mathrm{MgCl}_{2}$ & 1.46 \\
\hline $107 \mathrm{mM} \mathrm{K}_{2} \mathrm{SO}_{4}$ & 1.18 \\
\hline $300 \mathrm{mM}$ sucrose & 0.61 \\
\hline
\end{tabular}

*Ratio of the resistance $\left(\mathrm{C}_{50}\right)$ in the given medium to that in $\mathrm{KCl}$. The values are means of 2 measurements.

The influence of combined action of verapamil with polyene antibiotic amphotericin $\mathrm{B}$ in $160 \mathrm{mM} \mathrm{KCl}$ is presented as a competition plot (Fig.6). The reference concentrations of the hemolytic agent verapamil $\left(a_{0}\right)$ and of amphotericin $\mathrm{B}\left(b_{0}\right)$ were chosen in such a way that the rate of hemolysis at $a_{0}$ and $b_{0}$ were close to those at their $\mathrm{C}_{50}$ values. Next, the verapamil solution at concentration $a_{0}$ was mixed with amphotericin B solution at concentration $b_{0}$ in various proportions $(p)$ and the rate of hemolysis in these solutions was measured. In Fig. 6, the coordinate x presents the values of $p$ in the range from 0 to 1 . At $p=0$, verapamil is alone, while at $p=1$, amphotericin $\mathrm{B}$ is alone. At the other $p$ values, the concentrations $a$ and $b$ are varied together in such a way that $a=(1-p) a_{0}$ and $b=p b_{0}$. On the coordinate y, the rate of hemolysis $(V)$ is presented. The rate of hemolysis increases gradually with $p$ value increase to $p=$ 0.5 . In this proportion, the rate of hemolysis is about 10 times higher than the rate of hemolysis at $p=0$ (verapamil alone) and $p=1$ (amphotericin $\mathrm{B}$ alone). At $p$ values higher than $p=0.5$, the rate of hemolysis is diminished. The results indicate strong synergy between verapamil and amphotericin B.

Similar results were obtained with chlorpromazine and amphotericin B (Fig. 7). The highest synergistic effect between chlorpromazine and the polyene is observed at $p=0.5$. The rate of hemolysis is about 14 times higher then, the rate of hemolysis induced by these agents applied singly. An opposite effect on the rate of hemolysis was found for a combination of verapamil and chlorpromazine (Fig. 8). The lowest rate was obtained at $p=0.5$. The rate of hemolysis at $p=0$ and $p=1$ was about 2.5 times higher than at $p=0.5$. 


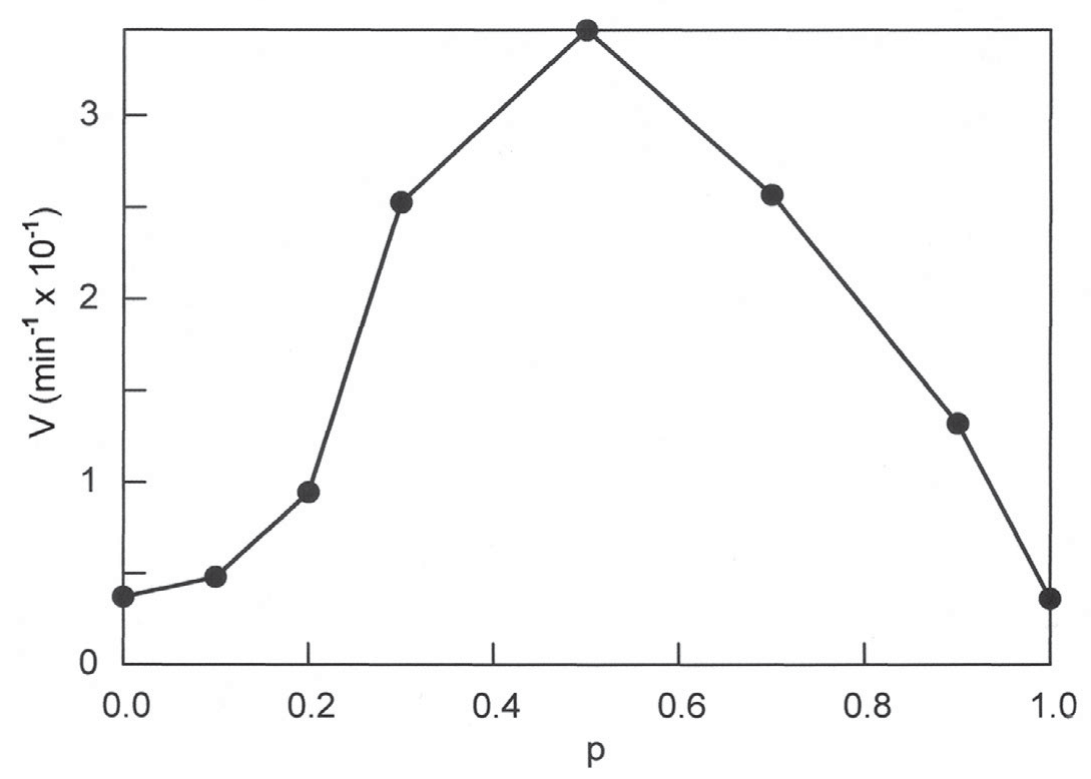

Fig. 6. Influence of combined action of verapamil with amphotericin B on the dependence of the rate of human erythrocyte hemolysis $(V)$ on $p$ (proportion of amphotericin $\mathrm{B}$ in the mixture). The reference concentration $a_{0}$ (verapamil) was $4.5 \mathrm{mM}$. The reference concentration $b_{0}$ (amphotericin B) was $2.0 \mu \mathrm{M}$. The concentrations were chosen so that the effect of verapamil and the polyene, applied singly, was equal to $\mathrm{C}_{50}$. Incubation medium: $160 \mathrm{mM} \mathrm{KCl}, 37^{\circ} \mathrm{C}$

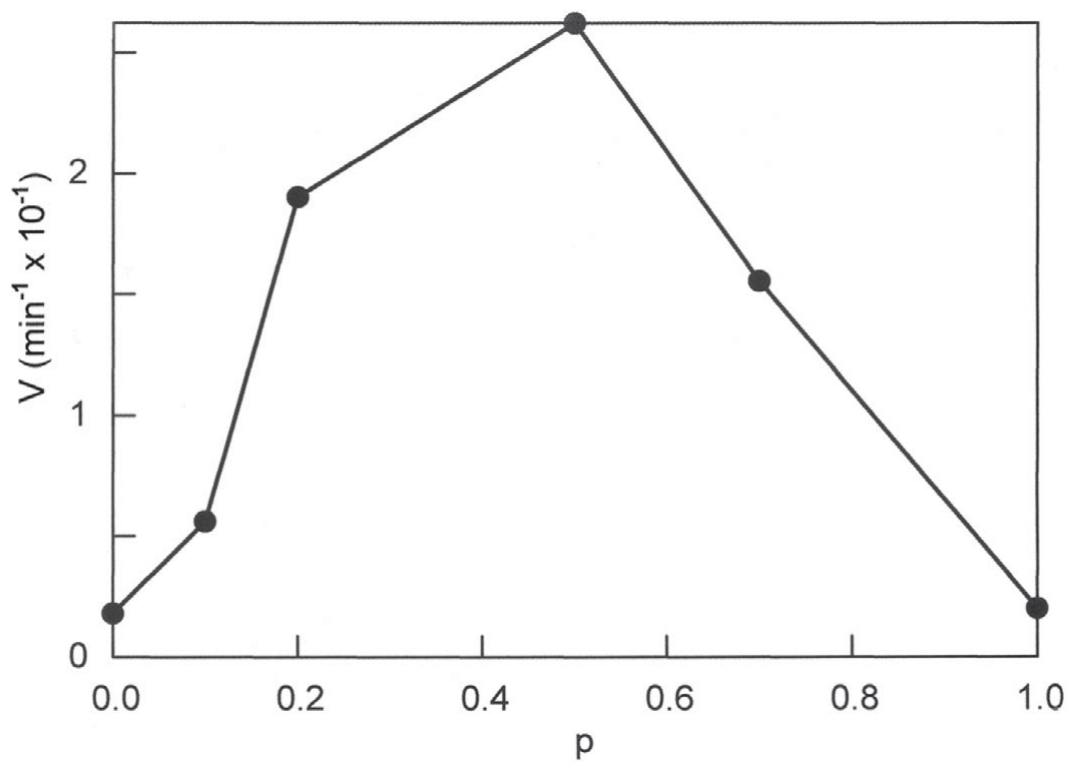

Fig. 7. Influence of combined action of chlorpromazine with amphotericin $B$ on the dependence of the rate of human erythrocyte hemolysis $(V)$ on $p$ (proportion of amphotericin B in the mixture). The reference concentration $a_{0}$ (chlorpromazine) was $0.20 \mathrm{mM}$. The reference concentration $b_{0}$ (amphotericin B) was $2.9 \mu \mathrm{M}$. Other explanations as in Fig. 6 


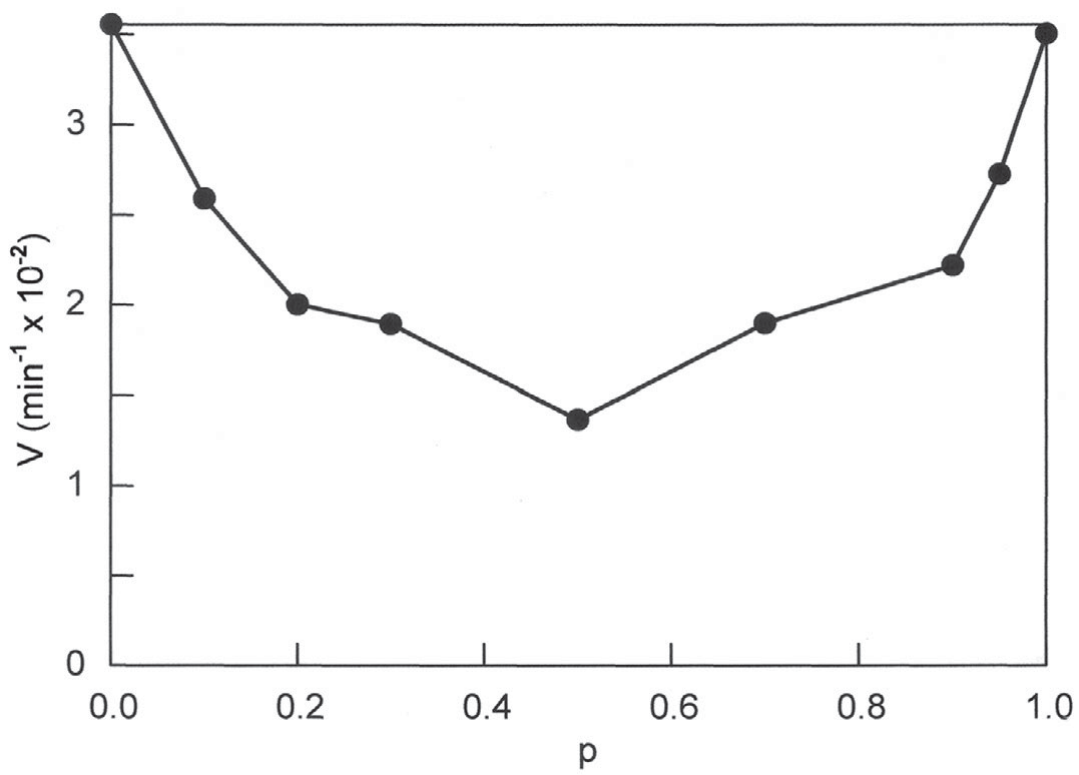

Fig. 8. Influence of combined action of verapamil with chlorpromazine on the dependence of the rate of human erythrocyte hemolysis $(V)$ on $p$ (proportion of chlorpromazine in the mixture). The reference concentration $a_{0}$ (verapamil) was $6.0 \mathrm{mM}$. The reference concentration $b_{0}$ (chlorpromazine) was $0.30 \mathrm{mM}$. Other explanations as in Fig. 6

\section{DISCUSSION}

In the present work, we investigated the hemolysis caused by the 2 amphipathic agents (verapamil and chlorpromazine) in various incubation conditions. Hemolytic concentrations of verapamil and chlorpromazine, used in the present paper, are similar to those reported earlier (KHASNOBIS et al. 1982; LieBER et al. 1984; HeNDRICH et al. 2002; WatTS \& HANDY 2007; Suwalsky et al. 2008, 2010). They are higher than the therapeutic and toxic concentrations of each of the agents alone. Therapeutic plasma concentrations of chlorpromazine range from 0.1 to $1 \mu \mathrm{M}$ (KOLAKOwSKA et al. 1976), or up to $5 \mu \mathrm{M}$ (Dorson et al. 1988). Toxic effects of the drug may appear by its plasma concentration equivalent to approximately $3 \mu \mathrm{M}$ (RIVERA-CALIMLIM et al. 1973). The range of therapeutic concentrations of verapamil at its typical dose during cardiac care is about $4 \mu \mathrm{M}$. However, overdosing would result in circulating verapamil concentration of around $325 \mu \mathrm{M}$ (WATTS \& HANDY 2007). Its toxicity appears above approximately $2 \mu \mathrm{M}$ verapamil in plasma (Musshoff et al. 2004). Such low concentrations of verapamil are not able to induce hemolysis. It was found that 5 $\mu \mathrm{M}$ verapamil only altered the shape of erythrocytes inducing stomatocytosis, while hemolysis is caused by $5 \mathrm{mM}$ verapamil (SuWALSKY et al. 2010). The last result is in agreement with our mean verapamil $\mathrm{C}_{50}$ value. 
The resistance of erythrocytes to verapamil is evidently higher than their resistance to chlorpromazine. The difference is most probably a consequence of higher chlorpromazine lipophilicity (PYKA et al. 2006). Both the agents are much less effective towards erythrocytes than the polyene antibiotic amphotericin B, studied earlier (KNopik-Skrocka \& Bielawski 2005; KnOPIK-SKrocka et al. 2006). The polyene is hemolytically active only in the self-associated form (BOLARD et al. 1991). Present results compared to critical micellar concentrations of chlorpromazine and verapamil (Aanismaa \& Seelig 2007) indicate that monomer forms of these agents are able to induce hemolysis.

No evident difference was found in the resistance of human and pig erythrocytes to verapamil. Similar results were earlier described for chlorpromazine-induced hemolysis in erythrocytes of various species of mammals (BIERY et al. 1978). In contrast, our previous studies with amphotericin B have revealed a high dependence of the polyene hemolytic activity on species-specific properties of the mammalian erythrocyte membrane (KNOPIK-SKROCKA et al. 2003; KNOPIK-SKROCKA \& BULDAŃCZYK 2004). Hence, it can be assumed that the hemolytic activity of verapamil and chlorpromazine, compared to amphotericin B, is much less sensitive to the species-specific differences in the molecular organization or composition of the mammalian erythrocyte membranes.

The kinetics of hemolysis induced by verapamil is very similar to that caused by chlorpromazine and can be classified as the permeability type of hemolysis (BIELAWSKI 1990). The process corresponds to that caused by amphotericin B (KNOPIK-SKROCKA $\&$ BIELAWSKI 2005). However, the rate of hemolysis induced by the polyene is greatly decreased in the presence of divalent cations, anions and disaccharides. The hemolysis caused by the polyenes is preceded by a high increase in erythrocyte suspension absorbance (KNOPIK-SKROCKA et al. 2003, 2007; KNOPIK-SKROCKA \& BULDAŃCZYK 2004). This increase is an effect of the faster efflux of $\mathrm{K}^{+}$, compared to the slower influx of divalent ions or disaccharides, and erythrocyte shrinkage. It has been interpreted that amphotericin B forms with membrane cholesterol highly selective channels (KNOPIK-SKRockA \& Bielawski 2002; KNOPIK-SKrocka et al. 2003, 2007).

By measuring chlorpromazine-induced uptake of mono- and disaccharides, LIEBER et al. (1984) concluded that chlorpromazine induces colloid osmotic hemolysis resulting not from the direct creation of large holes but from the opening of small holes, which lead to a selective increase in membrane permeability. According to the results of KATSU et al. (2007), chlorpromazine, similar to the polyene antibiotic filipin, forms in liposomes pores permeable simultaneously to $\mathrm{K}^{+}$and calcein. Their radius is higher than that of pores formed by amphotericin B (KATSU et al. 2007). From our previous kinetics studies, we concluded that filipin-induced hemolysis is of the damage type, which can be explained by formation of large perforations, permeable to substances of low molecular weight as well as macromolecules, including hemoglobin (KNOPIK-SKROCKA \& BIELAWSKI 2002; KNOPIKSKROCKA et al. 2003).

The present results show a low sensitivity of the hemolytic activity of verapamil and chlorpromazine to changes in the chemical composition of the incubation medium. Among the media examined, $\mathrm{CaCl}_{2}$ and $\mathrm{MgCl}_{2}$ are distinguished by the highest 
decrease in hemolytic activity of verapamil. Only a small increase in the resistance of erythrocytes to chlorpromazine is observed in the presence of divalent ions. In the sucrose medium, instead of the decrease, an increase in the hemolytic activity of chlorpromazine and verapamil is observed. We suggest that hemolysis induced by chlorpromazine as well as verapamil is an effect of the formation of pores with low selectivity. However, their diameter is not large enough to cause hemoglobin escape, typical for filipin action. The erythrocyte membranes treated with verapamil or chlorpromazine are more permeable to sucrose than to divalent cations. Divalent cations are known agents that interact with erythrocyte membranes and inhibit the activity of many pore-forming substances by screening of the membrane charges (BASHFORD et al. 1988). With regard to the protonated state of verapamil (PoHL et al. 1998), as well as chlorpromazine (AhyAyAuch et al. 2003; WiŚNIEWSKA \& WolNiCKA-GluBisz 2004), at $\mathrm{pH}$ under and near the physiological value, the activity of both the amphipaths in the media of divalent cations is not modified by salt formation.

The permeabilizing action of verapamil is increased in the presence of other MDR modulators (CASTAING et al. 2007). Combinations of chemical agents may exhibit a greater effect than that expected from the action of single agents (BERENBAUM 1989). A useful method for assessing synergy or antagonism is the competition plot proposed by CASTAING et al. (2007). This method was earlier described as a simple test of enzyme-catalyzed reactions (CHEVILlard et al. 1993; CARDENAS 2001). In the present study, the competition plot was also used to investigate the changes in hemolytic activity of verapamil and chlorpromazine, acting in combination with amphotericin B. We found that the hemolytic activity of verapamil and chlorpromazine is markedly enhanced in the presence of the polyene. The results indicate strong synergy between verapamil and amphotericin B, as well as between chlorpromazine and the polyene.

Amphotericin B is able to inhibit the hemolytic action of the polyene antibiotic filipin (BRAJTBURG et al. 1980). The antagonism between these polyenes is interpreted as the effect of competition for cholesterol as a membrane target (BRAJTBURG et al. 1980). The increase in membrane cholesterol content decreases the binding of verapamil to the membrane lipid bilayer (MAson et al. 1992). Cholesterol alters the lipid bilayer hydrocarbon core structure in a manner that makes verapamil partitioning into the membrane less energetically favorable. CASTAING et al. (2003a) show that cholesterol modifies the permeabilizing activity of verapamil and other MDR modulators. This effect is dependent on cholesterol proportion in the membrane. The interaction of chlorpromazine with lipid membranes is also reduced by the presence of cholesterol (LuXnat \& Galla 1986; TAKEgami et al. 1999; WiśniewsKa \& WolnicKa-Glubisz 2004; WolnickA-Glubisz et al. 2009). This effect was explained by the rigidifying effect of cholesterol and a decrease in amphipath partition coefficient.

One possible explanation of the potentiation of hemolytic activity of verapamil and chlorpromazine in combination with amphotericin B, may be associated with changes in the molecular organization of membrane cholesterol and increased accessibility of anionic phospholipids to verapamil or chlorpromazine. The increase in hemolytic activity of the polyene acting with verapamil or chlorpromazine can be explained by facilitation of the amphotericin-B-cholesterol interaction. 
The results obtained for the combination of verapamil with chlorpromazine indicate antagonism between these agents. A competition for the anionic phospholipids as membrane targets may be a reasonable explanation of this effect.

\section{REFERENCES}

Aanismaa P., Seelig A. 2007. P-glycoprotein kinetics measured in plasma membrane vesicles and living cells. Biochemistry 46: 3394-3404.

Ahyayauch H., Goni F. M., Bennouna M. 2003. pH-dependent effects of chlorpromazine on liposomes and erythrocyte membranes. J. Liposome Res. 13: 147-155.

Anteneodo C., Bisch P. M., Ferreira Marques J. 1995. Interaction of chlorpromazine with phospholipid membranes. Eur. Biophys. J. 23: 447-452.

Bashford C. L., Alder G. M., Graham J. M., Menestrina G., Pasternak C. A. 1988. Ion modulation in membrane permeability: effect of cations on intact cells and on cells and phospholipid bilayers treated with pore-forming agents. J. Membr. Biol. 103: 79-94.

Bebawy M., Morris M. B., Roufogalis B. D. 2001. Selective modulation of P-glycoprotein mediated drug resistance. Br. J. Cancer 85: 1998-2003.

Bennouna M., Ferreira-Marques J., Banerjee S., Caspers J., Ruysschaert J. M. 1997. Interaction of chlorpromazine with phospholipid membranes: a monolayer and a microelectrophoresis approach. Langmuir 13: 6533-6539.

Berenbaum M. C. 1989. What is synergy? Pharmacol. Rev. 41: 93-141.

BIELAWSKI J. 1990. Two types of hemolytic activity of detergents. Biochim. Biophys. Acta 1035: 214-217.

BIERY E., GIRI S. N., JAIN N. C. 1978. Rates of chlorpromazine-induced hemolysis in seven species of animals. J. Vet. Pharmacol. Therapeut. 1: 149-154.

Bolard J., Legrand P., Heitz F., Cybulska B. 1991. On-sided action of amphotericin B on cholesterol-contaning membranes is determined by itself-association in the medium. Biochemistry 30: $5707-5715$.

Brajtburg J., Medoff G., Kobayashi G., Elberg S., Finegold C. 1980. Permeabilizing and hemolytic action of large and small polyene antibiotics on human erythrocytes. Antimicrob. Agents Chemother. 18: 586-592.

CARdenas M. L. 2001. The competition plot: a kinetic method to assess whether an enzyme that catalyses multiple reactions does so at a unique site. Methods 24: 175-180.

Castaing M., Loiseau A., Cornish-Bowden A., 2007. Synergy between verapamil and other multidrug-resistance modulators in model membranes. J. Biosci. 32: 737-746.

Castaing M., Loiseau A., Mulliert G. 2003b. Interactions between verapamil and neutral and acidic liposomes: effects of the ionic strength. Biochim. Biophys. Acta 1611: 107-114.

Castaing M., Louse A., Gouda L. 2003a. Effects of cholesterol on dye leakage induced by multidrug-resistance modulators from anionic liposomes. Eur. J. Pharmacol. Sci. 18: 81-88.

Charbonneau C., Fournier I., Dufresne S., Barwicz J., Tancrede P. 2001. The interactions of amphotericin B with various sterols in relation to its possible use in anticancer therapy. Biophys. Chem. 91: 125-133.

Chen J. Y, Brunauer L. S., Chu F. C., Helsel C. M., Gedde M. M., Huestis W. H. 2003. Selective amphipathic nature of chlorpromazine binding to plasma membrane bilayers. Biochim. Biophys. Acta 1616: 95-105.

Chen J. Y., Huestis W. H. 1997. Role of membrane lipid distribution in chlorpromazine-induced shape change of human erythrocytes. Biochim. Biophys. Acta 1323: 299-309.

Chevillard Ch, Cardenas M. L., Cornish-Bowden A. 1993. The competition plot: a simple test of whether two reactions occur at the same active site. Biochem. J. 289: 599-604. 
Cybulska B., Bolard J., Seksek O., Czerwiński E., Borowski E. 1995. Identification of the structural elements of amphotericin B and other polyene macrolide antibiotics of the heptaene group influencing the ionic selectivity of the permeability pathways formed in the red blood cell membrane. Biochim. Biophys. Acta 1240: 167-178.

DeUtiCKE B. 1968. Transformation and restoration of biconcave shape of human erythrocytes induced by amphiphilic agents and changes of ionic environment. Biochim. Biophys. Acta 163: 494-500.

Dorson P. G., Crismon M. L. 1988. Chlorpromazine accumulation and sudden death in patient with renal insufficiency. Drug Intell Clin. Pharm. 22: 776-778.

Drori S., Eytan G. D., AssaraF Y. 1995. Potentation of anticancer-drug cytotoxicity by multidrugresistance chemosensitizers involves alterations in membrane fluidity leading to increased membrane permeability. Eur. J. Biochem. 228: 1020-1029.

Hagerstrand H., Mrówczyńska L., Salzer U., Prohaska R., Michelsen K., Kralu-Iglic V., Iglic A. 2006. Curvature-dependent lateral distribution of raft markers in the human erythrocyte membrane. Mol. Membr. Biol. 23: 277-288.

Hendrich A., Lichacz K., Burek A., Michalak K. 2002. Thioridazine induces erythrocyte stomatocytosis due to interactions with negatively charged lipids. Cell. Mol. Biol. Lett. 7: 10811086.

Katsu T., Imamura T., Komagoe K., Masuda K., Mizushima T. 2007. Simultaneous measurements of $\mathrm{K}^{+}$and calcein release from liposomes and the determination of pore size formed in a membrane. Analytic. Sci. 23: 517-522.

Khasnobis A. K., SAha J., Mukherjee B. P. 1982. In vitro hemolytic property of substituted phenothiazines. Ind. J. Pharmacol. 14: 305-308.

KNopiK-SKRockA A., BIELAWSKI J. 2002. The mechanism of the hemolytic activity of polyene antibiotics. Cell. Mol. Biol. Lett. 7: 31-48.

KnopiK-Skrocka A., Bielawski J. 2005. Differences in amphotericin B-induced hemolysis between human erythrocytes from male and female donors. Biological Lett. 42: 49-60.

Knopik-Skrocka A., Bielawski J., Gląi M., Klafaczyńska A., Wulkiewicz M. 2003. A kinetics study of pig erythrocyte hemolysis induced by polyene antibiotics. Cell. Mol. Biol. Lett. 8: 439-454.

Knopik-Skrocka A., Bielawski J., Kopczyński Z., Grodecka-Gazdecka S., TomcZak P., Gryczka R., Mazur-RoszaK M., KĘSA H. 2006. The susceptibility to amphotericin B-induced hemolysis of erythrocytes from women with breast cancer before and during therapy. Comp. Clin. Pathol. 15: 181-187.

Knopik-Skrocka A., Bielawski J., Wrzeszcz K., Bochanysz A., NowaK K. 2007. Modifications of hemolytic activity of polyene antibiotics by mono- and disaccharides in mammalian erythrocytes. Biological Lett. 44: 17-30.

KNopiK-SKRocka A., BuldaŃCZYK A. 2004. The response of horse erythrocytes to polyene antibiotics. Biological Lett. 41: 27-39.

Kolakowska T., Wiles D. H., Gelder M. G., McNeilly A. S. 1976. Clinical significance of plasma chlorpromazine levels. II. Plasma levels of the drug, some of its metabolites and prolactin in patients receiving long-term phenotiazine treatment. Psychopharmacol. 49: 101-107.

Lieber M. R., Lange Y., Weinstein R. S., Steck T. 1984. Interaction of chlorpromazine with the human erythrocyte membrane. J. Biol. Chem. 259: 9225-9234.

Lieberman J. A., Philipis M., Gu H., Stroup S., Zhang P., Kong L., Ji Z., Koch G., Hamer R. M. 2003. Atypical and conventional antipsychotic drugs in treatment-naive first-episode schizophrenia: a 52-week randomized trial of clozapine vs chlorpromazine. Neuropsychopharmacol. 28: 995-1003.

Luxnat M., Galla H. J. 1986. Partition of chlorpromazine into lipid bilayer membranes: effect of membrane structure and composition. Biochim. Biophys. Acta 856: 274-282.

Mason R. P., Moisey D. M., Shajenko L. 1992. Cholesterol alters the binding of $\mathrm{Ca}^{2+}$ channel blockers to the membrane lipid bilayer. Mol. Pharmacol. 41: 315-321. 
McTAVISH D., Sorkin D. 1989. Verapamil: an update review of its pharmacodynamic and pharmacokinetic properties and therapeutic use in hypertension. Drugs 38: 19-76.

Meier M., Li Blatter X., Seelig A., Seelig J. 2006. Interaction of verapamil with lipid membranes and P-glycoprotein: connecting thermodynamics and membrane structure with functional activity. Biophys. J. 91: 2943-2955.

Michalak K., Wesolowska O., Motohashi N., Hendrich A. B. 2007. The role of the membrane actions of phenotiazines and flavonoids as functional modulators. Top Heterocycl. Chem. 8: 223-302.

Morimoto Y., Yutani Y., Kado Y., Iida T., Shiota M., Takeuchi Y. 1995. Protective effects of neutral amino acids against amphipathic drug-induced hemolysis. Biol. Pharmacol. Bull. 18: $1535-1538$.

Musshoff F., Padosch S., Steinborn S., Madea B. 2004. Fatal blood and tissue concentrations of more than 200 drugs. Forensic Sci. Int. 142: 161-210.

Pajeva I. K., Wiese M., Cordes H.P., Seydel J. K. 1996. Membrane interactions of some catamphilic drugs and relation to their multidrug-resistance-reversing ability. J. Cancer Res. Clin. Oncol. 122: 27-40.

Perrotton T., Trompier D., Chang X., Di Pietro A., Baubichon-Cortay H. 2007. (R)- and (S)-verapamil differentially modulate the multidrug-resistant protein MRP1. J. Biol. Chem. 282: 31542-31548.

Pickholz M., Oliveira JR. O. N., Skaf M. S. 2007. Interactions of chlorpromazine with phospholipid monolayer: effects of the ionization state of the drug. Biophys. Chem. 125: 425-434.

Pohl E. E., Krylov A., V., Block M., Pohl P. 1998. Changes of the membrane potential profile induced by verapamil and propranolol. Biochim. Biophys. Acta 1373: 170-178.

PYKa A., BABUŚKA M., ZAChariasZ M. 2006. A comparison of theoretical methods of calculation of partition coefficients for selected drugs. Acta Pol. Pharm. - Drug Res. 63: 159-167.

Rivera-Calimlim R., Casteneda L., Lasagna L. 1973. Effects of mode of management on plasma chlorpromazine in psychiatric patients. Clin. Pharmacol. Therapy 14: 978-986.

Salerno M., Loechariyakul P., Saengkhae C., Garnier-Suillerot A. 2004. Relation between the ability of some compounds to modulate the MRP1-mediated efflux of gluthatione and to inhibit the MRP1-mediated efflux of daunorubicin. Biochem. Pharmacol. 68: 2159-2165.

Schreier S. L., Zachowski A., Devaux P. F. 1992. Mechanisms of amphipath-induced stomatocytosis in human erythrocytes. Blood 79: 782-786.

SheEtz M. P., Singer S. J. 1974. Biological membranes as bilayer couples. A mechanism of drugerythrocyte interactions. Proc. Natl. Acad. Sci. USA 71: 4457-4461.

Speelmans G., Staffhorst R. W., De Wolf F. A., De KruijfF B. 1995. Verapamil competes with doxorubicin for binding to anionic phospholipids resulting in increased internal concentrations and rates of passive transport of doxorubicin. Biochim. Biophys. Acta 1238: 137-146.

Suwalsky M., Munoz M., Mennickent S., Sotomayor C. P., Bolognin S., Zatta P. 2010. Structural effects of verapamil on cell membranes and molecular models. J. Chil. Chem. Sci. 55: 1-4.

Sunalsky M., Villena F., Sotomayor C.P., Bolognin S., Zatta P. 2008. Human cells and cell membrane molecular models are affected in vitro by chlorpromazine. Biophys. Chem. 135: 7-13.

Takegami S., Kitamura K., Kitade T., Hasegawa K., Nishinira A. 1999. Effects of particle size and cholesterol content on the partition coefficients of chlorpromazine and triflupromazine between phosphatidylcholine-cholesterol bilayers of unilamellar vesicles and water studied by second-derivative spectrophotometry. J. Colloid Interf. Sci. 220: 81-87.

Wadkins R., Houghton P. 1993. The role of drug-lipid interactions in the biological activity of modulators of multi-drug resistance. Biochim. Biophys. Acta 1153: 225-236.

Wajnberg E., Tabak M., Nussenzveig P.A., Lopes C.M., Louro S.R. 1988. pH-dependent phase transition of chlorpromazine micellar solutions in the physiological range. Biochim. Biophys. Acta 944: 185-190.

Watts T. J., Handy R. D. 2007. The haemolytic effect of verapamil on erythrocytes exposed to varying osmolarity. Toxicol. Vitro 21: 835-839. 
WiŚniewsKa A., WolnicKa-Glubisz A. 2004. ESR studies on the effect of cholesterol on chlorpromazine interaction with saturated and unsaturated liposome membranes. Biophys. Chem. 111: 43-52.

Wolnicka-Glubisz A, Lukasik M., Pawlak A., Wielgus A., Niziolek-Kierecka M., Sarna T. 2009. Peroxidation of lipids in liposomal membranes of different composition photosensitized by chlorpromazine. Photochem. Photobiol. Sci. 8: 241-247.

Zachowski A., Durand Рн. 1988. Biphasic nature of the binding of cationic amphipaths with artificial and biological membranes. Biochim. Biophys. Acta 937: 411-416. 